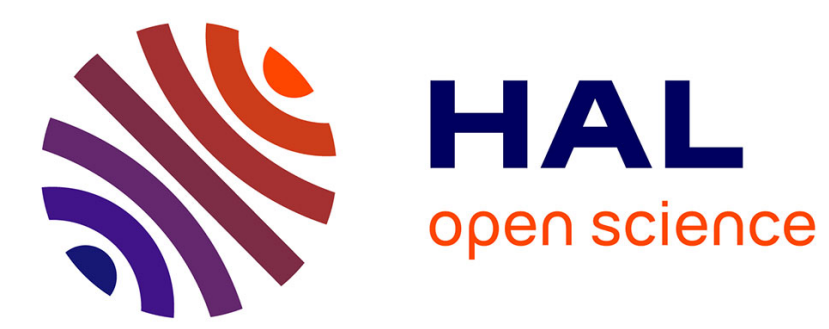

\title{
Logistics Pooling for City Supply
}

Jesus Gonzalez-Feliu, Nicolas Malhéné

\section{To cite this version:}

Jesus Gonzalez-Feliu, Nicolas Malhéné. Logistics Pooling for City Supply. Supply Chain Forum: An International Journal, 2014, 15 (4), pp.2-4. hal-01139476

\section{HAL Id: hal-01139476 \\ https://hal.science/hal-01139476}

Submitted on 10 Apr 2015

HAL is a multi-disciplinary open access archive for the deposit and dissemination of scientific research documents, whether they are published or not. The documents may come from teaching and research institutions in France or abroad, or from public or private research centers.
L'archive ouverte pluridisciplinaire HAL, est destinée au dépôt et à la diffusion de documents scientifiques de niveau recherche, publiés ou non, émanant des établissements d'enseignement et de recherche français ou étrangers, des laboratoires publics ou privés. 


\section{Logistics Pooling for City Supply}

Jesus Gonzalez-Feliu, EVS-PIESO, UMR 5600, Ecole des Mines de St Etienne, CNRS, France

Nicolas Malhéné, EIGSI, La Rochelle, France

Although often seen as essential for keeping city centers alive and thriving, urban logistics is usually associated with various nuisances, such as noise, pollution, and/or safety problems. Numerous solutions and actions of different natures have been experimented with around the world during recent years. Even if improvements have been measured, many of the actions highlight the difficulties facing stakeholders who want to collaborate. Collaborative logistics still appears to be a sweet dream, and goods are not yet consolidated in a way to rationalize transport flows and reduce the nuisance attributed to urban goods transport. However, Since 2010, collaboration and resource pooling are seen as potential subjects of research to advance a better rationalization of good transport flows in cities (Gonzalez-Feliu et al., 2013).

It is important to recall that the supply chain links raw materials to a final product located at the final consumption place (or to its sales place) in an interconnected set of processes, stages, goods, and information flows and with their related stakeholders. In this context, an action or modification made during the last miles of this supply chain can have impacts in all stages (Allen \& Browne, 2010). For that reason, it is important to approach the question of resource pooling and collaborative logistics using a systemic viewpoint, focusing on the different stages of the supply chain and not only on the final distribution to customers.

These collaboration and resource-sharing strategies can be of two types (Gonzalez-Feliu et al., 2013): horizontal collaboration takes place among stakeholders who act at a same stage (or echelon) of the supply chain and belong (or can belong) to different supply chains and are (or can be) in competition; vertical collaboration takes place among stakeholders who act in different (but correlated) echelons of the same supply chain and are complementaryin that coordination and collaboration seem more natural.

Collaborative logistics is a popular subject in supply chain management research (Barratt, 2004; Jain \& Dubey, 2005; Simatupang \& Sridharan, 2002; Stefansson, 2006). However, collaboration in city logistics historically has been addressed in public-private collaboration, in a public planner's viewpoint, without entering in detail into private-private relations and supply chain interactions (Gonzalez-Feliu et al., 2014; Taniguchi \& Thompson, 2014). In the last five years, communities of practice have highlighted the need to address collaborative urban logistics and resource pooling also using a supply chain viewpoint for better efficiency of actions and practices, at both research and practice levels (Gonzalez-Feliu and Morana, 2011).

This increasing interest by research and practice stakeholders led us to develop the present special issue of Supply Chain Forum: An International Journal entitled "Logistics Pooling for 
City Supply." The issue focuses on logistics pooling actions and methods created to improve the city's supply efficiency, not only reflecting the viewpoint of last-mile logistics but also taking a systemic viewpoint of collaborative logistics and, more precisely, of resource pooling. This choice takes into account that urban logistics need to be planned and managed in relation to supply chains, and that supply chain choices also can affect urban logistics. This issue focuses then on proposals that facilitate collaborative and pooling-based logistics in order to implement freight flow pooling actions to deliver to cities. Such approaches can take part at different echelons of the supply chain but have as an ultimate target delivering to final customers in urban zones. The refereeing process has resulted in eight articles representing different natures and disciplinary provenances.

One of the most interesting topics that is nowadays less explored in city logistics is the question of quantifying the flows that enter the city. In this context, Guerrero, Nierat, and Proulhac aim to identify the role of urban areas in the freight system and examine the nature and intensity of interurban freight flows in France from the French shippers' survey in a vision of urban goods needs. The authors sketch a first picture of the geography of freight flows with regard to the light they shed on economic interactions between urban centers. Their analysis shows the hierarchical nature of inter-urban freight flows to supply cities in France: it appears from their work that large urban areas are supplied by smaller ones. The authors also propose practical implications of their work.

Also focusing on goods that have to be transported to cities, that is, on inbound flows, Lendjel and Fischman analyze the transaction costs formation of river transport, mainly through canalizing flows to cities. Based on the analysis of existing container barge transport (CBT) chains, the authors point out the following obstacles impeding their use for urban river logistics: the complexity of these chains on the one hand and the level of specificity of assets involved in the loading-unloading phases on the other hand. On the basis of transaction costs economics theories, the authors show how several innovations involving barge transport to supply French cities share a common aim to diminish transaction costs. Finally, the article points out the need to coordinate and pool resources to help integrated governance structures organize regular inland shipping lines necessary to supply dense French urban areas.

In the proximity of cities, and mainly in small and medium urban areas, transport is organized by regional or inter-regional strategies, and in some supply chains transportation routes can contain items for urban customers from different cities, which have to be delivered the same day with the same vehicle and with time and demand variability constraints that make it difficult to tactically plan this type of distribution. Mancini addresses this difficulty to optimize urban delivery routes by taking into account that they are inserted into regional logics by putting in synergy all those constraints resulting in a unified framework. First, the author defines and characterizes the main types of constraints related to this type of distribution and, via a literature analysis, presents the main combinatorial optimization problems developed to deal separately with these constrains. After that, the article introduces a real-life vehicle-routing problem, as well as a real case related to regional freight distribution in Piedmont (northwest Italy), which is assessed by a fast heuristic method. The article concludes by discussing the portability of the proposed framework. 
On the last echelon of supply chains we find interface with end consumers. In this context, Blanquart and Carbone analyze collaboration in supply chains in terms of proximity, focusing on the needs of urban consumers. The authors start by reviewing the literature, which is completed by the deployment and analysis of 23 semi-directive interviews to define a typology of proximity after examining the collaboration opportunities and limitations for each category. The authors state that the nature of the relationships among the different actors in the collaboration shows different degrees of importance related to environmental concerns and potential sustainable performance of the SC. The article concludes by presenting and discussing several would-be preconditions for developing effectively collaborative supply chains.

Another level of collaboration can be that of warehousing. Indeed, consumers in urban areas need goods but the management of their supply is often steered by production or inventorying strategies. Pellicanò, Gatusso, and Cassone propose a framework to simulate and assess collaborative warehouse management policies. This work is based in the concept of intelligent warehouses, ITS, and specific automation. After setting the background for the functional management of logistics platforms using ITS and specific automation, the authors propose the specification, calibration, and test of a stochastic, dynamic, discrete-event micro-simulation model to analyze inbound trucks and goods management. The final goal is to reduce the time costs related to receiving goods. After calibrating the model, the authors propose a case to illustrate possible applications of the proposed framework.

The three last articles of this issue are related to one of the key subjects in urban logistics, which deals directly with the question of resource pooling and collaboration: urban consolidation. First, a simulation framework that addresses the questions of collaboration among carriers using urban consolidation centers (UCCs) is presented. Then, two complementary articles address the question of collaboration and economic viability of UCCs via a set of case studies.

Battaia, Faure, Marquès, Guillaume, and Montoya-Torres contribute to the assessment of UCC's impacts by examining the collaborative aspects of carriers in competition that (or potentially can) use the UCC. Authors mobilize several fields of knowledge, such as operational research, game theory, and transportation science among others, into an integrated assessment framework that aims to anticipate the activity level of a UCC and determine the condition under which it generates benefits for carriers. The aim is to provide a suitable support to public decision makers in their territorial management choices. The authors apply the proposed framework in a test case for the city of Saint-Etienne, France, as an illustration, and conclude by addressing the implications of the obtained results for public decision makers.

Gonzalez-Feliu, Malhéné, Morganti, and Morana also address the question of urban consolidation viability by a systematic qualitative analysis to study the levers that affect the success factor of UCC deployment. The authors focus on two macro categories of UCCs: those deployed to deliver to the city (or city center) and located in peripheral areas and those located close to a specific area to serve it. Starting from an initial typology of experiments, 
obtained from a systematic analysis of 34 experiences from two countries, France and Italy, the authors orient the study toward the analysis of six models of cooperation strategies set up to reach an economic viability of these platforms. Those models are then explored in depth on the basis of a four-element grid: steering, organization, development, and financing. From the proposed typology and the analysis of the six case experiences, the authors reflect on the main elements that influence the search for economic viability in urban consolidation and distribution platforms. The article concludes describing the need for collaboration and practical implications of the analysis for UCC deployment.

Finally, Allen, Browne, Woodburn, and Leonardi also examine UCC viability through the viewpoint of interfacing with the supply chain. If the two preceding works regard horizontal collaboration in UCCs, this article focuses on vertical collaboration, that is, how UCCs can be used in the supply chain to reduce last-mile traffic and its associated environmental impacts while also helping to make supply chains more responsive and efficient and thereby generate commercial benefits. After presenting the role of UCCs and discussing their various types, the authors present six case studies of UCC schemes and trials, comparing them on the basis of the following three-element grid: objectives, operational characteristics, and impacts. The authors examine critical success factors associated with UCCs and conclude with practical implications for the development of those types of platforms.

\section{References}

Allen, J., \& Browne, M. (2010). Sustainability strategies for city logistics. In A. McKinnon, S. Cullinane, M. Browne, \& A. Whiteing (Eds.), Green logistics: Improving the environmental sustainability of logistics (pp. 282-305). London: Kogan Page.

Barratt, M. (2004). Understanding the meaning of collaboration in the supply chain. Supply Chain Management: An International Journal, 9(1), 30-42.

Gonzalez-Feliu, J., \& Morana, J. (2011). Collaborative transportation sharing: from theory to practice via a case study from France. In Yearwood, J.L. and Stranieri, A. (eds.), Technologies for Supporting Reasoning Communities and Collaborative Decision Making: Cooperative Approaches, Hershey: Information Science Reference, 252-271.

Gonzalez-Feliu, J., Morana, J., Salanova Grau, J. M., \& Ma, T. Y. (2013). Design and scenario assessment for collaborative logistics and freight transport systems. International Journal of Transport Economics, 40(2), 207-240.

Gonzalez-Feliu, J., Semet, F., \& Routhier, J. L. (2014). Sustainable urban logistics: Concepts, methods and information systems. Heidelberg: Springer.

Jain, K., \& Dubey, A. (2005). Supply chain collaboration: A governance perspective. Supply Chain Forum: An International Journal, 6(2), 50-57.

Simatupang, T. M., \& Sridharan, R. (2002). The collaborative supply chain. The International Journal of Logistics Management, 13(1), 15-30.

Stefansson, G. (2006). Collaborative logistics management and the role of third-party service providers. International Journal of Physical Distribution \& Logistics Management, 36(2), 7692.

Taniguchi, E., \& Thompson, R. G. (Eds.). (2014). City logistics: Mapping the future. Boca Raton, FL: CRC Press. 